Article

\title{
The Tenuous Use of Exergy as a Measure of Resource Value or Waste Impact
}

\author{
Kyrke Gaudreau $^{1}{ }^{*}$, Roydon A. Fraser ${ }^{2}$ and Stephen Murphy ${ }^{1}$
}

1 Environment and Resource Studies, University of Waterloo, Waterloo, Ontario, N2L 3G1, Canada; E-Mail: sd2murph@uwaterloo.ca

2 Mechanical and Mechatronics Engineering, University of Waterloo, Waterloo, Ontario, N2L 3G1, Canada; E-Mail: rafraser@uwaterloo.ca

* Author to whom correspondence should be addressed; E-Mail: kgaudrea@uwaterloo.ca; Tel.: +1-519-729-7758; Fax: +1-519-746-0292.

Received: 5 November 2009 / Accepted: 19 December 2009 / Published: 23 December 2009

\begin{abstract}
Exergy is a thermodynamic concept that has been widely promoted for assessing and improving sustainability, notably in the characterization of resources and wastes. Despite having many notable benefits, exergy is often misused by authors who tend to apply it as an intrinsic characteristic of an object (i.e., as a static thermodynamic variable). Using both theoretical and empirical evidence the authors present five key limitations that must be overcome before exergy can be applied to characterize objects: (1) the incompatibility between exergy quality and resource quality; (2) the inability of exergy to characterize non work-producing resources via the concentration exergy; (3) the constraints placed on the derivation of exergy; (4) problems with the exergy reference environment; and (5) the multiple perspectives applied to exergy analysis. Until the limitations are addressed, exergy should only be used for its original purpose as a decision making tool for engineering systems analysis.
\end{abstract}

Keywords: exergy; resource value; waste impact; sustainability assessment 


\section{Introduction}

In recent years, the use of exergy analysis has been promoted as a thermodynamic tool for assessing and improving sustainability [1-14]. For example, when discussing the assessment of green energy technology, Rosen and Dincer argue that exergy analysis provides information that is more useful and more meaningful than energy analysis [4]. Due to its notable benefits and promotion by thermodynamic experts, exergy is applied—oftentimes for the purpose of sustainability — in several different disciplines, including: ecology [1-3,15-24]; complex systems [3,16,25]; resource accounting and lifecycle assessments [8,11,14,26-37]; engineering [4,10,12,13,38-52]; and even social theory [53].

Despite its popularity and noted benefits, exergy is often being misused. Specifically, in many applications the exergy value of an object is assigned as if it were intrinsic to that object. In other words, exergy is used to characterize the object, and assigns a static thermodynamic value to that object. Unfortunately, such an application of exergy has not been well established, and does not follow from the formulation of exergy.

This paper will present a new perspective on the derivation and application of exergy. The objective of this paper is to argue that exergy is not a static thermodynamic property of a substance. Specifically, the authors will argue that exergy should not be used to uniquely characterize the physical value of a resource, nor the impact of a waste, both of which are fundamental to the use of exergy for sustainability. Instead, exergy and exergy analysis should be applied only for its original purpose; as a decision making tool with the general goal of improving process efficiency as measured by work or work potential, or by identifying areas of exergy destruction or entropy production.

The limiting of exergy to systems analysis has implications for how exergy is applied in scientific investigation. For example, the use of exergy to measure water quality [54] or to compare efficiencies in lifecycle assessments $[8,36]$ must be revisited, as well as any policy recommendations following from the research.

The outline of the paper is as follows: a historical background of the attempts to use exergy to quantify wastes is presented. Following this, the use of exergy to characterize resources will be discussed. Finally, arguments will be provided as to why exergy is not suited for either resource valuation or waste impact. Before beginning the discussion, the authors would like to note the following clarifications. In this paper, unless otherwise noted, all references to 'exergy' refer to non-flow exergy. This is keeping in agreement with the authors discussed in paper. Secondly, when the term 'resource value' is used, it refers to physical resource value, as opposed to economic or aesthetic resource value, which is once again keeping in agreement with the authors discussed in this paper.

\section{Attempts to Characterize Waste Impact Using Exergy}

The connection between the exergy content of a waste is not new, and dates back to the early 1990s, with the work of Crane et al., and the even earlier works of well-known exergy researchers, such as Szargut, Reistad, Gaggioli and Rosen [39], and Wall [26].

To discuss exergy as a measure of waste impact, the term 'waste' must be defined. Ao, Gunnewiek and Rosen define a waste emission as "a release to the environment of a material not considered 
usable" [38]. Using this definition, Ao, Gunnewiek and Rosen then provide a compelling argument that links exergy to waste impact, which is as follows [38]:

Exergy can ... be viewed as a measure of the departure of a substance from equilibrium with a specified reference environment, which is often modeled as the actual environment.... The exergy of an emission to the environment, therefore, is a measure of the potential of the emission to change or impact the environment. The greater the exergy of an emission, the greater is its departure from equilibrium with the environment, and the greater may be its potential to change or impact the environment

Other researchers have proposed similar arguments [4,5,8,10,39,43-45,47,54-58]. One consequence of this argument connecting exergy to waste is that a substance in equilibrium with the environment has no exergy and no ability to cause harm $[38,44]$, and this has led to the promotion of zero exergy emission processes in lifecycle assessments [36].

Despite the seeming simplicity of the argument linking exergy to waste impact, there has been very little formal agreement amongst researchers as to whether it is valid or not, and how it should be applied. For example, Rosen's work in the 1990s found little correlation between exergy and waste impact [44,45] and, Ayres and Favrat both claim that exergy cannot measure toxicity [56,59]. Similarly, Szargut argues that exergy is not proportional to impact [60]. However, other authors contradict Szargut by claiming that waste impact, as measured by exergy, is additive, and therefore proportional $[54,55,57,58]$.

To add to the confusion, some authors have claimed that the exergy embodied in the waste is the minimum work required to bring the waste into equilibrium with the reference environment $[44,45,54,57,61]$, while others have claimed the exergy embodied in waste is a measure of work that may be produced by bringing the waste into equilibrium with the reference environment [62,63]. Furthermore, some authors are not even consistent about whether the exergy embodied in a waste represents work potential, or work required [30]. It must be mentioned, however, that the definition of exergy - maximum useful to the dead state work [64] - directly contradicts the interpretation that it may require work to bring a substance into equilibrium with the reference environment. By definition and derivation, non-flow exergy is always positive for any system out of equilibrium with its reference environment, or zero if in equilibrium with its reference environment. That is, to interpret the exergy embodied in waste as a work requirement is to effectively assign a negative exergy value to the waste, and this contradicts the requirement that exergy is always positive.

In a recent critical review of exergy indicators of waste emissions, Ao and Rosen concluded that exergy could be a meaningful indicator of environmental impact if researchers could develop "reliable, objective, and widely accepted exergy-based indicators" [38]. However, in light of Rosen's earlier work that found little correlation $[44,45]$, the vision that exergy could be a meaningful indicator of waste impact does not mean that it is.

Based on the disagreements above, it is easy to see how using exergy to characterize the impact of a waste product on the environment currently has little to offer any form of environmental or sustainability assessment. A researcher adopting an exergy perspective would not know whether they should assume exergy is proportional or not to waste impact (and if not, what should they do?), nor 
whether the exergy embodied in the waste is even a bad thing (it may provide useful work or other benefits as per the saying, "one person's waste is another person's gain (or raw material)").

\section{Applying Exergy to Characterize Resources}

While the use of exergy to characterize waste impact has created some measure of debate and disagreement, the use of exergy to characterize the physical value of a resource is a proposal that appears to be generally accepted [7,11,14,26-31,34,35,54,55,65]. In this section, the authors will argue that similar to the problems in linking exergy to waste impact, linking exergy to resource value is almost equally problematic. This section will begin by outlining the argument to use exergy as a measure of resource value.

\subsection{Linking Exergy to Resource Value}

The argument to use exergy to measure resource value begins with the 'observation' that resource consumption is not well quantified using matter or energy, primarily because both are conserved $[4,8,11,26,34]$. In other words, from the perspective of the first law of thermodynamics there is no such thing as resource consumption, and resource consumption is improperly defined $[36,66]$.

To quantify how important aspects of a resource change during consumption, exergy proponents invoke the second law of thermodynamics by noting that resource consumption is analogous to the degradation of the resource quality $[26,36,66]$. In other words, the degradation of exergy in a resource is a measure of the amount by which the value of the resource is consumed. Following from this, the exergy content of a resource is a measure of the value of a resource $[5,6,9,11,14,26,34,36,60,67,68]$. To quote Valero et al. and Szargut et al., "the thermodynamic value of a natural resource can be defined as the minimum work necessary to produce it with a specific structure and concentration from common materials in the environment" [31,34,35]. Valero goes on to relate the exergy content of the Earth to the Earth's 'natural capital' [34].

\subsection{Problems with Relating Exergy to Resource Value}

While the theoretical argument connecting exergy to resource value described above has some intuitive appeal, there are theoretical and empirical problems that have not been addressed. In the following section, the authors will present two such problems with linking exergy to the value of a resource.

\subsubsection{Theoretical problem - the different perspectives of exergy}

The first problem regarding exergy and resource value is that of multiple perspectives. Simply put, it is difficult to reconcile how exergy may be simultaneously the value of a resource and the impact of a waste. Both resources and wastes are, by definition, out of equilibrium with the reference environment; otherwise, they would have no exergy content, and no value and/or no ability to cause 
harm. However, the exergy content of a resource may just as easily be interpreted as the ability of the resource to cause harm, as it is the value of the resource. In other words, there is no a priori reason why exergy represents value or harm for a given item (resource or waste). This is illustrated in Figure 1 below.

Figure 1. Different perspectives taken on the same two thermodynamic items.

\section{Resource Perspective} Item 2 is twice as valuable as Item 1

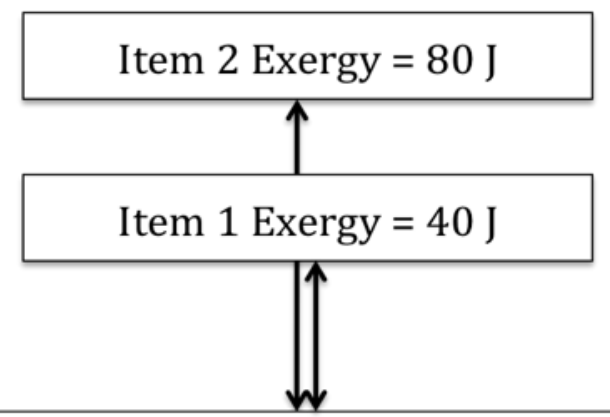

\section{Environment}

Waste

Perspective

Item 2 is twice as harmful as Item 1

Exergy is a context sensitive thermodynamic concept because it is always measured with respect to a reference environment $[13,14,26,34,46]$. However, this context sensitivity only provides the thermodynamic distance between the item (resource or waste) and the reference environment. This context sensitivity says nothing about how this thermodynamic distance may be interpreted. The interpretation of the thermodynamic distance is a question of perspective. Unfortunately, exergy is blind to perspective, and any perspective applied to exergy is provided by the researcher, and not by the concept itself.

Rosen addresses the harmful/helpful perspectives of exergy by arguing that the difference is whether the exergy is constrained or not $[4,40,43,44]$. According to Rosen, "most resources found in the environment are constrained and are by virtue of their exergy of value, while unconstrained emissions of exergy are free to impact in an uncontrolled manner on the environment" [43]. These authors would argue that Rosen's approach still requires refinement before accepting exergy as a measure of resource value or waste impact. For example, sunlight, water, and wind, are three vital, but unconstrained, resources. Furthermore, while sunlight, water, and wind are all considered resources (i.e., electricity generation, photosynthesis), too much of them at a given time may cause harm (i.e., sunburn, flooding, and tornadoes). In this respect, the perspective required to discern harmful from helpful exergy is not solely a matter of constraint. Despite the potential incompleteness of Rosen's approach, it is noteworthy that he has explicitly addressed the question of perspectives of exergy.

To slightly broaden the discussion of exergy perspectives, it should be noted that within the ecological and systems literature, exergy is often understood as the means by which self-organizing systems self-organize. Some notable examples include the work of Kay et al., Jorgensen, and even some later publications by the Emergy group [1,2,19,20,22,64,69-73]. The issue, once again, is whether the perspective of exergy as causing self-organization is valid, and under what conditions. 


\subsubsection{Empirical problem — the lack of empirical validation}

A second concern regarding using exergy to value resources is that the proposal has not undergone much empirical validation. Instead, for the most part, the proposal that exergy is a useful metric to characterize resource value or waste impact appears to almost have the status of a law, most often in the realm of exergy lifecycle assessments and resource accounting methodologies [8,36,50-52].

In a recent dissertation, Valero produced some empirical results that may be reanalyzed to better understand the relation between exergy and resource value [34],. The data from Valero related to the relationship between the theoretical chemical exergy value of a mineral resource and the amount of work required to upgrade the resource from a mixture to the pure state. Essentially, Valero was assessing the relationship between theory and reality. Valero produced two scaling factors, $k_{c h}$ and $k_{c}$ (the k-factors), that show the multiplicative difference between the theory and experimental results. The k-factors shown are shown in equation form in Equation 1 [34]:

$$
\begin{aligned}
& B_{c h}^{\exp }=k_{c h} * B_{c h}^{\text {theo }} \\
& B_{c}^{\exp }=k_{c} * B_{c}^{\text {theo }}
\end{aligned}
$$

where $B_{c h}{ }^{e x p}$ and $B_{c}{ }^{e x p}$ are the actual chemical and concentration work required to upgrade the mineral, while $B_{c h}{ }^{\text {theo }}$ and $B_{c}{ }^{\text {theo }}$ are the predicted work requirements (these are the theoretical chemical and concentration exergies). The larger the k-factor, the weaker is the relationship between theoretical and empirical exergy values. Valero compiled scaling factors for a variety of minerals, the first twenty of which are listed in Table 1 [34].

Table 1. Selected $\mathrm{k}_{\mathrm{ch}}$ and $\mathrm{k}_{\mathrm{c}}$ values — chemical and concentration exergy scaling factors.

\begin{tabular}{|l|l|l|l|l|l|}
\hline Substance & $\boldsymbol{k}_{\boldsymbol{c}}$ & $\begin{array}{l}\boldsymbol{k}_{\boldsymbol{c}} \\
\boldsymbol{h}\end{array}$ & Substance & $\boldsymbol{k}_{\boldsymbol{c}}$ & $\boldsymbol{k}_{\boldsymbol{c h}}$ \\
\hline $\mathrm{Ag}$ & 7,042 & 10 & $\mathrm{Cs}$ & N.A. & 1 \\
$\mathrm{Al}$ & 2,250 & 8 & $\mathrm{Cu}$ & 343 & 80.2 \\
$\mathrm{As}$ & 80 & 10 & $\mathrm{~F}$ & 2 & 1 \\
$\mathrm{Au}$ & 422,879 & 1 & $\mathrm{Fe}$ & 97 & 5.3 \\
$\mathrm{Ba}$ & $\mathrm{N} . \mathrm{A}$. & 1 & $\mathrm{Ga}$ & N.A. & 1 \\
$\mathrm{Be}$ & 112 & 1 & $\mathrm{Ge}$ & N.A. & 1 \\
$\mathrm{Bi}$ & 90 & 10 & $\mathrm{Hf}$ & N.A. & 1 \\
$\mathrm{Cd}$ & 804 & 10 & $\mathrm{Hg}$ & 1,707 & 10 \\
$\mathrm{Co}$ & 1,261 & 10 & $\mathrm{In}$ & N.A. & 10 \\
$\mathrm{Cr}$ & 37 & 1 & $\mathrm{~K}$ & 39 & 1 \\
\hline
\end{tabular}

Source: adapted from [34].

While Table 1 is not complete, it is representative of the $k$-values listed by Valero in [34]. In general, $k_{c}$ fluctuates widely, from a low of unity to a high of over 400,000 . By contrast, $\mathrm{k}_{\mathrm{ch}}$ generally 
stays within one order of magnitude (from 1 to 10), with a high of 188 for U, which is not shown here [34].

The variations in $k_{c h}$ and $k_{c}$ shown in Table 1 indicate very little correlation between the theoretical exergy value and the empirical results. Furthermore, since the variation in $k_{c}$ is over several orders of magnitude, it impossible to predict even approximate trends between theoretical exergy calculations and reality.

There are several possible reasons for the wide divergence between theoretical and empirical exergy value. For example, the reference environment may be inappropriately modeled. In her dissertation, Valero does critique her own choice for reference environments, Szargut's defined reference states, by noting that it "should not be considered as a dead [reference environment], but rather as a mathematical tool for obtaining standard chemical exergies of the elements" [34]. Potential reasons for the disjunction between theory and reality will be discussed in the following section, and includes problems with the reference environment formulation.

\section{Deconstructing the Fundamentals of Exergy}

In the section above, both a theoretical and an empirical argument were used to describe the difficulties encountered when relating exergy to resource value. The current section will deconstruct the basics of exergy by introducing four fundamental limitations with both the formulation and application of exergy. These limitations include:

1. The compatibility limitations between exergy quality and resource quality

2. The inability of exergy to characterize non work-producing resources via the concentration exergy

3. The limitations due to the derivation of exergy

4. Problems regarding the exergy reference environment

A fifth limitation, relating to the dual perspectives of exergy, has already been discussed above. This problem is equally valid as the above four, but the point should not be belabored further.

\subsection{The Compatibility Limitations between Exergy Quality and Resource Quality}

The first limitation of exergy, and one that lies at the heart of this discussion is whether exergy in fact represents a measure of resource quality. Earlier in this article, the primary argument for adopting exergy as measure of resource consumption was presented: energy and mass are both conserved, while exergy is not. Furthermore, resource consumption is analogous to the degradation of the resource quality, where this quality is measured by exergy. However, with reference to Valero's $k$-values, this argument must be revisited.

One key to understanding the primary argument hinges on the definition of quality. Exergy measures the quality of energy of a system where:

the quality of energy is related to the amount of useful work that can be obtained by bringing the system into equilibrium with its reference environment. 
For work-producing resources such as fossil fuels or biomass, exergy is often an appropriate measure of how much work can be extracted from these resources. However, for non work-producing resources such as minerals, the quality of the resource is not likely the amount of useful work that can be extracted from the resource. In other words, useful work is not a relevant characteristic of a mineral resource; in general there are other physical elements of practical value that are not work related.

To extend the discussion of the definition of resource quality, there are valuable resources that have little or no exergy, and for which exergy is clearly not capable of characterizing resource value. This is most fundamentally demonstrated by the example of air as illustrated in Figure 2.

Figure 2. Both air and fuel are necessary for the oxidization process, but air is considered valueless while the fuel has value.

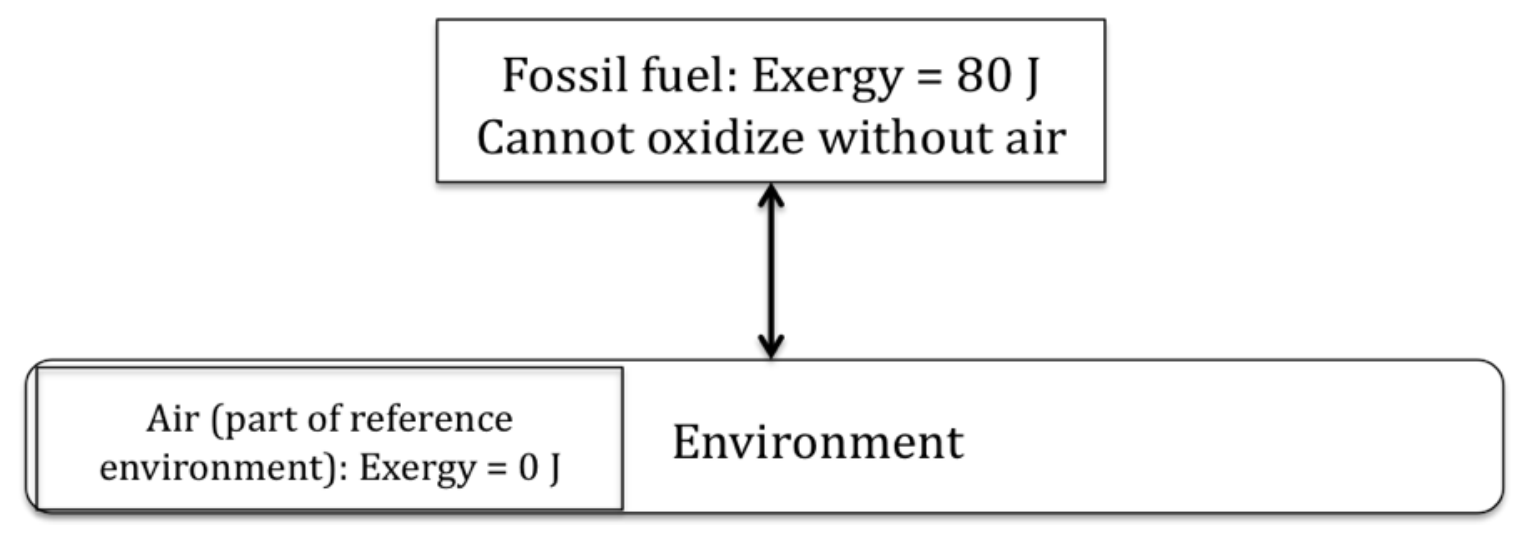

With respect to the situation depicted in Figure 2, Ahrendts' research into reference environments led him to one possible reference environment where air was considered more valuable than fossil fuels. Ahrendts called this reversal of value a 'paradox' [74].

Paradox or not, the issue remains that both the exergy measure of value and the exergy quantification of value (where fuels have value and air has none) is problematic. A full discussion of resource value is out of the scope of this article, although the topic is discussed elsewhere, such as in [33]. What this article will address is one subset of the larger topic, namely a potential reason why energy quality (useful work) is not a relevant characteristic of a mineral. This topic is discussed in the following section where the relevance of the concentration exergy is examined.

\subsection{Using Concentration Exergy to Determine Useful Work Production}

To introduce the second limitation of exergy, it is useful to revisit Valero's k-values discussed above, and shown in Table 1. Within Valero's k-values, it was the concentration exergy, represented by the $\mathrm{k}_{\mathrm{c}}$ term, that showed the least relationship between theoretical and empirical exergy values. To discuss some reasons why there is so little correlation between theoretical and empirical concentration exergies, the derivation of the concentration exergy is provided.

The derivation of the concentration exergy appears to be commonly performed via the Guoy-Studola theorem [for instance, see 34,75]. To quote Çengel, Çerçi and Wood, "the beauty of working with reversible processes is that we can work with the process that we feel most comfortable 
with, and then apply the results to the reverse process by simply reversing the directions of the interactions" [75]. The Guoy-Studola theorem is necessary to apply the results in a reverse manner.

The Guoy-Studola theorem is shown in Equation 2 [76]:

$$
W_{\text {lost }}=B_{\text {destroyedi }}=T^{o} S_{\mathrm{gen}}
$$

where $\mathrm{W}_{\text {lost }}$ is the work lost during a process, which is equal to the exergy destroyed $\left(\mathrm{B}_{\text {destroyed }}\right)$. $\mathrm{T}^{\mathrm{o}}$ is the temperature of the reference environment, and $S_{\text {gen }}$ is the entropy generated during the process.

Other qualifiers needed to derive the concentration exergy are the assumptions of ideal solutions (based upon ideal gases), constant temperature, and constant pressure. These assumptions are made by Çengel, Çerçi and Wood [75] as well as the Exergoecology group [34,60]. It must also be noted that for the Guoy-Studola to be applied in integrated form, as shown in Equation 2, the temperature must be constant.

By assuming ideal gases, the derivation of the concentration exergy is relatively simple, because it follows from the entropy of mixing. For an ideal gas at constant temperature and pressure, the entropy produced by component ' $i$ ' in mixing is related to the change in volume as given in Equation 3 [34]:

$$
s_{\text {gen, } i}=R \ln \frac{V_{t o t}}{V_{i}}=-n_{i} R \ln x_{i}
$$

where $V_{1}$ is the original volume of the ideal gas, $V_{\text {tot }}$ is the total volume of the mixing chamber (final volume of the ideal gas), For ideal gases, the ratio between partial volumes is equal to the mole fraction [76] represented by $x_{i}$. The negative sign indicates that entropy generation monotonically increases with the inverse of the mole fraction - that is, entropy generation occurs when the mole fraction decreases, as the gas is dispersed/mixed over a larger volume.

Using the Guoy-Studola theorem, the work lost, or exergy destroyed, is simply the entropy generated multiplied by the absolute temperature as shown in Equation 4 [75]:

$$
W_{\text {lost }}=B_{\text {destroyedi }}=B_{c, i}=T^{o} S_{\text {gen }, i}=-n_{i} R T^{o} \ln x_{i}
$$

where the exergy destroyed, $B_{\text {destroyed, } i,}$ is also the concentration exergy $B_{c, i}$, in this case by the invoking the idea that the mixing process can be reversibly reversed (vis-à-vis Çengel, Çerçi, and Wood [75]). Equation 4 forms the basis of calculating exergy as applied to resource value determination. $B_{c, i}$, the concentration exergy of element $i$, is identical to Valero's theoretical concentration exergy, $B_{c}^{\text {theo }}$, shown in Equation 1.

While it is possible to theoretically determine how much work can be produced via the concentration exergy, to extract useful work from the mixing process requires both a (potentially infinite) source of heat from the environment, and the existence of 'semi-permeable' membranes: membranes that block the passage of some substances of choice while allowing all other substances to pass through unhindered. At this point, semi-permeable membranes are mostly only theoretical constructs in the sense that these authors do not know of any real set of semi-permeable membranes that can selectively pass all the substances of choice in a mixture. For example, molecular sieves that may pass small molecules or atoms but not large are semi-permeable, but to complete the set one also needs a membrane that passes the large molecules or atoms but not the small, something a simple molecular sieve cannot do. 
Putting aside concerns about semi-permeable membranes and how to actually extract work from concentration exergy in practice, an obvious problem with the concentration exergy is that if a substance is present in the system but not present in the reference environment then it will have infinite concentration exergy. The reason for this is that the final molar concentration $x_{i}$ of the non-environment substance will be zero (actually, $x_{i}$ is not exactly zero, $x_{i}$ approaches zero). Correspondingly, the concentration exergy approaches infinity as the natural logarithm of $x_{i}$ approaches zero (keep in mind the negative sign in Equation 4).

Beyond the theoretical limitations to chemical exergy as given in Equation 4 described above (ideal solution, constant temperature, constant pressure, semi-permeable membranes and membrane set, and need for all system substances to be a priori present in the environment), one must also discuss the technical limitations related to extracting concentration exergy. To extract work via the semi-permeable membranes, the substance of choice must push the semi-permeable membrane into the reference environment since the work extracted from the concentration exergy is pressure-volume $(\mathrm{P} \Delta \mathrm{V})$ work. However, this requires both that the semi-permeable membrane is free to expand infinitely (into the infinite reference environment), and that there is some means to capture this $\mathrm{P} \Delta \mathrm{V}$ work. These requirements mean that serious limits exist on the ability to extract work from concentration exergy to the point that in many cases it may well be technically impossible. The only known application of semi-permeable membranes to these authors is that of osmosis, which is a very specific and limited application. Furthermore, the difficulty of constructing a complete set of semi-permeable membranes just makes this task of extracting concentration exergy that much harder. As for reversing the direction of the semi-permeable membranes (i.e., in the ideal process) in an attempt to increase a resource's concentration exergy, the technical limitations are just as great. In this regard, one should not be surprised to find the exergy input actually needed to create a resource concentration is many times larger than, and shows no correlation to, the concentration exergy, as provided by Valero's k-values once again.

To summarize, the concentration exergy does not appear to be a relevant form of work production or resource forming work input. These authors propose that this is the major reason for the wide divergence of Valero's $k_{c}$ values. Determining exergy, and useful work, based on the concentration exergy is simply not realistic.

To relate this back to valuing resources via exergy, it seems clear that the concentration exergy does not provide a meaningful means of valuing resources. The concentration exergy is, in many respects, a pure theoretical abstraction that has little correlation to any meaningful empirical characteristics. There is no meaning derived from contrasting the value of different resources based upon their concentration exergies. Unfortunately, as will be argued in the next section, the concentration exergy underpins the very derivation of exergy.

\subsection{Problems with the Fundamental Derivation of Exergy}

The third limitation regarding the applicability of exergy relates to the formulation of exergy, and how it places constraints on its application. It will be argued that the fundamental derivation of non-flow chemical exergy depends entirely on the concentration exergy. To explain this dependence on the concentration exergy, key points of Bejan's [76] derivation of non-flow exergy will be quoted. 
While Bejan's derivation includes mechanical, thermal, and chemical exergy terms, only chemical exergy will be discussed here, primarily because it is the only form of exergy used to value resources.

Bejan describes the system as a mixture containing $N_{1}, N_{2}, \ldots N_{\mathrm{n}}$ moles of n constituents. According to Bejan, "the initial equilibrium state of the system is characterized by the temperature $(\mathrm{T})$, pressure $(P)$, and $n$ chemical potentials $\left(\mu_{1}, \mu_{2}, \ldots, \mu_{\mathrm{n}}\right)$ which differ from the corresponding environment specific properties $\left(T_{0}, P_{0}, \mu_{0,1}, \mu_{0,2}, \ldots, \mu_{0, n}\right)$ " [76]. Note, the emphasis on equilibrium is placed by the authors, and not by Bejan.

Bejan approaches the derivation of non-flow chemical exergy by posing the question [76]: "What is the maximum useful work that could be produced as the system and the environment reach equilibrium?" This maximum useful work is related to temperature and pressure differences between system and environment, and (more important for this article) differences in chemical potentials between system and environment. According to Bejan [76], "these [mole] numbers change as each of the $n$ constituents diffuses through its own semi-permeable membrane that makes up the system-environment boundary."

From Bejan's description, it is possible to draw some potentially surprising conclusions regarding the derivation of exergy, and subsequently surprising consequences for the application of exergy. These conclusions are based upon the following three requirements imposed on the derivation of non-flow exergy:

1. Requirement 1: Both the system and the reference environment are in a state of internal equilibrium, as mentioned in the first Bejan quote.

2. Requirement 2: For every chemical species, there exists a semi-permeable membrane, as mentioned in the second Bejan quote.

3. Requirement 3: Every chemical species present in the system is also present in the reference environment. Without this requirement, even the minutest quantity of a chemical species would have infinite exergy, as was explained above.

The first conclusion to be drawn from a strict application of the requirements above is that the first and third non-flow exergy requirements are inherently in conflict. This is easily seen through an example. Imagine a fossil fuel as the system of interest with the atmosphere as its environment. In this case both the fossil fuel and the atmosphere can be in states of internal equilibrium thus satisfying the first requirement. However, since fossil fuels are not considered a component of the atmosphere they therefore have infinite exergy, which violates the third requirement. Likewise, if the fossil fuel is considered part of the environment, then the environment is no longer in equilibrium, thereby violating the first requirement.

The second conclusion, which follows from the first conclusion, is that when a system substance is not present in its environment, chemical exergy can no longer be quantified, based upon the constraints placed on the derivation. Notice in the fossil fuel example given in the previous paragraph that the infinite exergy presents itself in the absence of considering chemical reactions which is bizarre since all practical methods of extracting work (i.e., exergy) from fossil fuels is through oxidization chemical reactions.

The third conclusion, which has already been alluded to, is that a system composed of a mixture of a reactant (e.g., fuel, mineral) and an oxidizer (e.g., oxygen) cannot be characterized by non-flow 
exergy since such a mixture system is inherently in a state of chemical non-equilibrium, a violation of the first requirement. From a practical perspective this conclusion is nonsensical. For example, a fuel/air mixture in a compression ignition engine has a maximum work potential that is well established to be characterized by exergy [77,78]. One solution to this inherent violation of the first requirement is to make the first requirement less stringent. This will be discussed in the following section.

The fourth conclusion is that as far as the authors are aware there are significant practical difficulties to realizing semi-permeable membranes for all substances present in a given system/environment combination. These difficulties were discussed in the previous section and represent a substantial challenge to realizing Requirement 2. As a result it could be argued that an alternative physical derivation of chemical exergy is needed that avoids the use of semi-permeable membranes, but this is beyond the scope of this paper.

Based on the above four exergy conclusions, it appears that what many authors claim to be non-flow chemical exergy may in fact be a different thermodynamic concept or at least a restricted version of the exergy concept. That is, the very derivation of non-flow chemical exergy appears to limit both its scope and relevance.

Before discussing the fourth fundamental problem with exergy, the problems with the reference environment, a brief discussion of possible changes to the derivation of exergy described above is provided.

Rethinking the derivation of non-flow chemical exergy

What seems needed is a rethink about exergy and how it balances conceptual theoretical limits (e.g., reversible processes, infinite expansion into the environment) with practical world considerations (e.g., existence of the physics needed to access exergy, finite size environments). This rethink may include finite time considerations as discussed below. Although it is beyond the scope of this paper, the reader may be interested in knowing that one of the authors has previously proposed such a broadening of the concept of exergy, tentatively termed 'generalized exergy', by differentiating between types of exergy based on practical restrictions (i.e., intrinsic, transport, restricted, accessible, restricted-access, extracted, and hidden exergies) in addition to the conventional exergy types based on gradient source (e.g., mechanical pressure exergy, thermal exergy, chemical exergy) [64]. Also, the concept of generalized exergy acknowledges the existence of finite environments.

An example of how the exergy derivation may be rethought is to revise the requirements placed upon the system and the reference state. For example, Bejan's first requirement, that the system and the reference environment are in a state of internal equilibrium, may be relaxed as follows (and this may very well have been Bejan's intent, just not explicitly stated):

Possible Revised Requirement 1: Both the system and the reference environment are in a state of internal equilibrium or 'pseudo'-equilibrium.

Pseudo-equilibrium is a standard assumption applied to enable a far from equilibrium system to be described using equilibrium property values. A pseudo equilibrium state exists when all individual substances or groups of substances can thermodynamically be well described by equilibrium property values even while the system as a whole is far from equilibrium [79]. For example, a natural gas and 
air mixture at room temperature is far from equilibrium yet the natural gas and air are independently well described by their thermodynamic equilibrium property values. In effect, a state of pseudo equilibrium accounts for disparities in thermodynamic relaxation times; natural gas and air come quickly into thermal and mechanical pressure equilibrium but not chemical equilibrium making time an important consideration.

Another Possible Revision to Requirement 1: The reference environment is in a state of internal equilibrium or pseudo-equilibrium.

In this case there is no mention of the initial system state since conceptually there should be no reason to expect the initial system to be in equilibrium at all; all that is expected is that non-flow exergy represent the maximum amount of useful work that can be extracted as a system comes into equilibrium with its reference environment. In any event, a rethink of the requirements for calculating exergy would seem in order, an endeavor that is beyond the scope of this paper.

\subsection{Problems with Formulating the Reference Environment}

The fourth challenge that exergy must overcome relates to problems with the formulation of the reference environment. A complete discussion of the exergy reference environment is beyond the scope of this article. However, a detailed discussion is provided in Chapter 2 of [80], or in selected works of Rosen and Dincer (for example [10,45]).

As previously mentioned, one of the properties of exergy is that it is context sensitive because it is always measured with respect to a reference environment. These authors question whether the natural environment is an appropriate analogue for the exergy reference environment, and vice versa.

Both the Exergoecology group [31,34,35] and Ahrendts [74] have proposed exergy reference environments that attempt to combine important characteristics of both an ideal infinite reference environment and the natural environment. Both formulations have been critiqued for their respective weaknesses. For example, Rosen and Dincer describe the Exergoecology reference environment as "economic in nature", "vague and arbitrary with respect to the selection of reference substances", and is "not similar to the natural environment" [44]. Likewise, Ahrendts' reference environment has been critiqued by the Exergoecology group for not being empirically correct and for failing to meet Szargut's Earth Similarity Criterion, which argues that a reference environment substance must be abundant in the world [31]. Furthermore, both Ahrendts' and the Exergoecology group's reference environments are based on the requirement of chemical equilibrium, despite the Exergoecology group's claim that the natural world is not in equilibrium and therefore an equilibrium world cannot be used as a reference environment [31,34].

To help contrast the difference between the reference environment and the natural environment, two descriptions of 'environment' are provided; one relates to the exergy reference environment while the other describes an ecosystem, which forms part of our natural environment.

"The reference environment is in stable equilibrium, and has all parts at rest relative to one another. No chemical reactions can occur between the reference environment components. Further, the reference environment acts as an infinite system, is a sink and source for heat and materials, and experiences only internally reversible processes in 
which its intensive state remains unaltered (i.e., its temperature, pressure and chemical potentials for each of the components present remains constant)" [45].

"[The natural, or ecosystem environment is] an open, hierarchical, self-designing system of subsystems that in turn are an interconnected, interrelated, interacting network of information generating direct and indirect effects [81].

These two descriptions of the environment are at odds with each other. The important characteristics of the exergy reference environment (most notably: infinite, equilibrium, and reversible reactions) are opposed to the non-equilibrium, hierarchical, self-designing nature of the natural environment. Furthermore, the equilibrium/non-equilibrium divide makes any hybrid reference environments involving both environment descriptions either artificial/arbitrary in selection, not representative of a systems relevant environment, or demanding of a rethink of what really constitutes a system's reference environment.

When using exergy to characterize the value of a resource, or impact of a waste, a reference environment must be chosen. However, based on the short discussion of the reference environment provided above, it is possible to see how the requirements of the reference environment can severely limit the applicability of exergy. For example, with respect to exergy being a measure of waste impact, it is very difficult to understand how a waste product can harm a reference environmental that is infinitely large, and 'experiences only internally reversible processes in which its intensive properties remain unaltered' [45]. Likewise, for a resource to have value (have exergy), it must be out of equilibrium with the environment. But what does it mean for a resource to be 'out of equilibrium' with the natural environment, when the natural environment itself is non-equilibrium? Furthermore, how can the exergy of the resource be calculated with respect to the natural environment? Finally, if the natural environment is replaced by an ideal (equilibrium, infinite) reference environment, how does this impact the interpretation of resource value? These are all questions that matter if exergy is to provide any insight to environmental and sustainability issues.

\section{Discussion—Synthesizing the Challenges to Exergy}

The proceeding sections have ideally introduced some fundamental problems with the derivation and use of exergy when applied to resource value or waste impact. Despite this, exergy has merit. However, to take advantage of the abilities of exergy, one must return to its original purpose. Exergy was originally developed and applied as an analysis tool, generally within the discipline of engineering systems analysis. For example, exergy is often used to optimize power generation systems $[4,10,46]$, such as the Rankine cycle shown in Figure 3, where the Rankine cycle system is delineated by the dashed line.

As a systems analysis (decision making) tool, exergy may help locate inefficiencies and irreversibilities within the process or system at hand. For example, in the Rankine example of Figure 3, much of the incoming exergy is destroyed within the boiler, and therefore the boiler would be an ideal location to improve efficiency and reduce losses.

In applying exergy to characterize the value of a resource or the impact of a waste, exergy analysis is now often no longer being used as a systems analysis tool. Instead, exergy is applied as a static 
thermodynamic property, and becomes a characteristic of a specific item. For example, in the Ranking cycle of Figure 3, one resource measure of interest would be exergy of the incoming coal. The conceptual change from system to item focus is shown in Figure 4.

Figure 3. Example systems analysis view of exergy: a Rankine cycle.

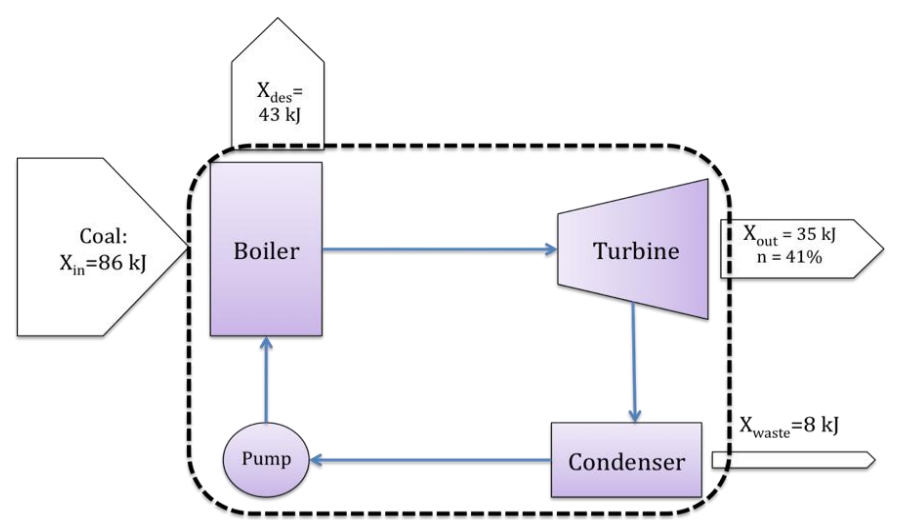

Figure 4. Example resource analysis view of exergy: coal viewed in isolation as a resource.

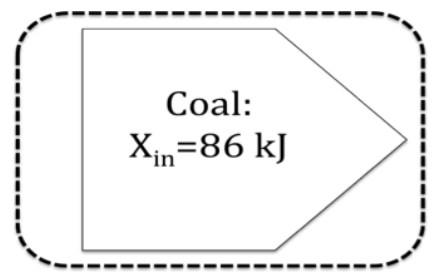

Valero describes the shift from "systems-analysis diagnosis" (systems-based) to a quantification of the "exergy resources on Earth" (item-specific) as involving "definitions of the environment, reference or dead state [that] are extremely different" [33]. These authors propose an even stronger claim: the shift from systems-analysis to item-specific perspectives of exergy requires a complete reformulation of exergy. Such a reformulation of exergy would need to overcome the five limitations of exergy discussed in the paper: (1) the compatibility limitations between exergy quality and resource quality; (2) the inability of exergy to characterize non work-producing resources via the concentration exergy; (3) the limitations due to the derivation of exergy; (4) problems regarding the exergy reference environment; and (5) the multiple perspectives applied to exergy analysis. Addressing these five limitations of exergy represent a direction for future research.

\section{Conclusions}

The application of exergy as a measure of resource value and waste impact has not been well established. Furthermore, based upon the arguments presented in this paper, exergy is in general not a valid measure of resource quality or waste impact. Until the limitations of applying exergy as a static thermodynamic concept have been addressed, the authors argue that exergy should only be used within the discipline of systems analysis and optimization, the original discipline for which exergy was developed. Exergy is not a static thermodynamic property. 
This paper outlined five key challenges to exergy analysis that must be if exergy is to provide any insight to environmental and sustainability assessments beyond its use in systems design and optimization. The five challenges are: (1) the incompatibility between exergy quality and resource quality; (2) the inability of exergy to characterize non work-producing resources via the concentration exergy; (3) the constraints placed on the derivation of exergy; (4) problems with the exergy reference environment; and (5) the multiple perspectives applied to exergy analysis. Until the limitations are addressed, exergy should only be used for its original purpose as a decision making tool for engineering systems analysis.

\section{Acknowledgements}

The authors would like to acknowledge the National Science and Engineering Research Council, whose support made this research possible.

\section{References and Notes}

1. Jorgensen, S.E. Eco-Exergy as Sustainability; WIT Press: Boston, MA, USA, 2006; Vol. 16, p. 207.

2. Kay, J.J.; Boyle, M. Self-Organizing, Holarchic Open Systems (SOHO). In The Ecosystem Approach: Complexity, Uncertainty, and Managing for Sustainability; Waltner-Toews, D., Kay, J.J., Lister, N.M., Eds.; Columbia University Press: New York, NY, USA, 2008.

3. Kay, J.J.; Boyle, M.; Regier, H.A.; Francis, G. An ecosystem approach for sustainability: addressing the challenge of complexity. Futures 1999, 31, 22.

4. Rosen, M.A.; Dincer, I.; Kanoglu, M. Role of exergy in increasing efficiency and sustainability and reducing environmental impact. Energ. Policy 2008, 36, 128-137.

5. Rosen, M.A. Can exergy help us understand and address environmental concerns? Int. J. Exergy 2002, 2,4 .

6. Brodianski, V.M. Earth's Available Energy and the Sustainable Development of Life Support Systems. In Encyclopedia of Life Support Systems; Unesco: Oxford, UK, 2002.

7. Chen, G.Q. Exergy consumption of the earth. Ecol. Model. 2005, 184, 363-380.

8. Cornelissen, R.L. Thermodynamics and Sustainable Development-the Use of Exergy Analysis and the Reduction of Irreversibility; $\mathrm{PhD}$ Thesis, University of Groningen: Groningen, The Netherlands, 1997.

9. Dincer, I.; Rosen, M.A. Thermodynamic aspects of renewables and sustainable development. Renew. Sust. Energ. Rev. 2005, 9, 169-189.

10. Dincer, I.; Rosen, M.A. Exergy-Energy, Environment and Sustainable Development, 1st ed.; Elsevier: Oxford, UK, 2007.

11. Gong, M.; Wall, G. On exergy and sustainable development—part 2-indicators and methods. Int. J. Exergy 2000, 1, 17.

12. Hepbasli, A. A key review on exergetic analysis and assessment of renewable energy resources for a sustainable future. Renew. Sust. Energ. Rev. 2008, 12, 593-661. 
13. Rosen, M.A.; Dincer, I. Exergy as the confluence of energy, environment and sustainable development. Int. J. Exergy 2001, 1, 11.

14. Wall, G.; Gong, M. On exergy and sustainable development-part 1: conditions and concepts. Int. J. Exergy 2000, 1, 18.

15. Kay, J.J. On complexity theory, exergy and industrial ecology: Some implications for construction ecology. In Construction Ecology: Nature as the Basis for Green Buildings; Kibert, C., Sendzimir, J., Guy, B., Eds.; Spon press: London, UK, 2002; pp. 72-107.

16. Kay, J.J. An introduction to systems thinking. In The Ecosystem Approach: Complexity, Uncertainty, and Managing for Sustainability; Waltner-Toews, D., Kay, J.J., Lister, N.M., Eds.; Columbia University Press: New York, NY, USA, 2008.

17. Kay, J.J.; Allen, T.; Fraser, R.; Luvall, J.; Ulanowicz, R. Can we use energy based indicators to characterize and measure the status of ecosystems, human, disturbed and natural. In Proceedings of the International Workshop: Advances in Energy Studies: Exploring Supplies, Constraints and Strategies, Porto Venere, Italy, May 23-27, 2000; pp. 121-133.

18. Kay, J.J.; Schneider, E.D. Thermodynamics and Measures of Ecological Integrity. In Proceedings of the International Symposium on Ecological Indicators, Fort Lauderdale, FL, USA,

October 19-19, 1990; Vol. 1.

19. Schneider, E.D.; Kay, J.J. Life as a manifestation of the Second Law of Thermodynamics. Math. Comput. Model. 1994, 19, 24.

20. Bastianoni, S.; Facchini, A.; Susani, L.; Tiezzi, E. Emergy as a function of exergy. Energy 2007, 32, 1158-1162.

21. Bastianoni, S.; Marchettini, N. Emergy/exergy ratio as a measure of the level of organization of systems. Ecol. Model. 1997, 99, 33-40.

22. Jorgensen, S.E. Evolution and exergy. Ecol. Model. 2007, 203, 490-494.

23. Jorgensen, S.E.; Nielsen, S.N. Application of exergy as thermodynamic indicator in ecology. Energy 2007, 32, 673-685.

24. Susani, L.; Pulselli, F.M.; Jorgensen, S.E.; Bastianoni, S. Comparison between technological and ecological exergy. Ecol. Model. 2006, 193, 447-456.

25. Homer-Dixon, T. The Upside of Down-Catastrophe, Creativity and the Renewal of Civilization; Alfred A. Knopf Canada: Toronto, Canada, 2006; Vol. 1.

26. Wall, G. Exergy-A Useful Concept within Resource Accounting; Institute of theoretical physics: Goteborg, Sweden, 1977.

27. Wall, G. Exergy conversion in the Swedish society. Resour. Energ. 1987, 9, 55-73.

28. Wall, G. Exergy conversion in the Japanese society. Energy 1990, 15, 435-444.

29. Wall, G.; Sciubba, E.; Naso, V. Exergy use in the Italian society. Energy 1994, 19, 1267-1274.

30. Zaleta-Aguilar, A.; Ranz, L.; Valero, A. Towards a unified measure of renewable resources availability: the exergy method applied to the water of a river. Energ. Convers. Manage. 1998, 39 , 1911-1917.

31. Szargut, J.; Valero, A.; Stanek, D.; Valero, A. Towards and international legal reference environment. In Proceedings of the ECOS 2005, Trondheim, Norway, 2005; pp. 409-420. 
32. Valero, A., Thermoeconomics as a conceptual basis for energy-ecological analysis. In Proceedings of the International Workshop on Advances in Energy Studies-Energy Flows in Ecology and Economy, Porto Venere, Italy, 27-31 May 1998; pp. 415-444.

33. Valero, A. Exergy accounting: capabilities and drawbacks. Energy 2006, 31, 164-180.

34. Valero, A. Exergy Evolution of the Mineral Capital on Earth; PhD Thesis, University of Zaragoza: Zarazoga, Spain, 2008.

35. Valero, A.; Ranz, L.; Botero, E. Exergetic Evaluation of Natural Mineral Capital (1) Reference Environment Methodology. In Proceedings of the ECOS 2002, Berlin, Germany, July 3-5, 2002; pp. 56-61.

36. Cornelissen, R.L.; Hirs, G.G. The value of the exergetic life cycle assessment besides the LCA. Energ. Convers. Manage. 2002, 43, 1417-1424.

37. Wall, G. Exergetics; Bucaramanga: Molndal, Sweden, 1998.

38. Ao, Y.; Gunnewiek, L.; Rosen, M.A. Critical review of exergy-based indicators for the environmental impact of emissions. Int. J. Green Energ. 2008, 5, 87-104.

39. Crane, P.; Scott, D.S.; Rosen, M.A. Comparison of exergy of emissions from two energy conversion technologies, considering the potential for environmental impact. Int. J. Hydrogen Energ. 1992, 17, 345-350.

40. Dincer, I.; Rosen, M.A. The Intimate Connection Between Exergy and the Environment. In Thermodynamic Optimization of Complex Energy Systems; Bejan, A., Mamut, E., Eds.; Kluwer Academic Publishers: Dordrecht, The Netherlands, 1999; Vol. 1, pp. 221-230.

41. Rosen, M.A. Energy crisis or exergy crisis? Int. J. Exergy 2002, 2, 3.

42. Rosen, M.A. Exergy and government policy: is there a link? Int. J. Exergy 2002, 2, 3.

43. Rosen, M.A. Assessing energy technologies and environmental impacts with the principles of thermodynamics. Appl. Energ. 2002, 72, 427-441.

44. Rosen, M.A.; Dincer, I. On exergy and environmental impact. Int. J. Energ. Res. 1997, 21, 643-654.

45. Rosen, M.A.; Dincer, I. Exergy analysis of waste emissions. Int. J. Energ. Res. 1999, 23, 1153-1163.

46. Rosen, M.A.; Dincer, I. Effect of varying dead-state properties on energy and exergy analyses of thermal systems. Int. J. Therm. Sci. 2004, 43, 121-133.

47. Rosen, M.A.; Gunnewiek, L. Relation between the exergy of waste emissions and measures of environmental impact. Int. J. Environ. Pollution 1998, 10, 261-272.

48. Utlu, Z.; Hepbasli,A. Energetic and exergetic assessment of the industrial sector at varying dead (reference) state temperatures: a review with an illustrative example. Renew. Sust. Energ. Rev. 2008, 12, 1277-1301.

49. Hepbasli, A.; Dincer, I., Effect of reference state on the performance of energy and exergyevaluation of geothermal district heating systems: Balcova example. Build. Environ. 2006, 41, 699-709.

50. Bakshi, B.R. A thermodynamic framework for ecologically conscious process systems engineering. Comput. Chem. Eng. 2002, 26, 269-282.

51. Hau, J.L.; Bakshi, B.R. Expanding exergy analysis to account for ecosystem products and services. Environ. Sci. Technol. 2004, 38, 3768-3777. 
52. Hau, J.L.; Bakshi, B.R. Promise and problems of emergy analysis. Ecol. Model. 2004, 178, 215-225.

53. Spiegelman, E.; Spiegelman, G.; Spiegelman, J. Money as social exergy. J. Bioeconomics 2007, 9 , 265-277.

54. Chen, G.Q.; Ji, X. Chemical exergy based evaluation of water quality. Ecol. Model. 2007, 200, 259-268.

55. Huang, L.Q.; Chen, G.Q.; Zhang, Y.; Chen, B.; Luan, S.J. Exergy as a unified measure of water quality. Commun. Nonlinear Sci. Numer. Simulat. 2007, 12, 663-672.

56. Ayres, R.U.; Ayres, L.W.; Martinas, K. Exergy, waste accounting, and life-cycle analysis. Energy 1998, 23, 355-363.

57. Sciubba, E. Exergy as a direct measure of environmental impact. In Proceedings of the ASME Advanced Energy Systems Division; ASME: New York, NY, USA, 1999; Vol. 39, pp. 571-581.

58. Sciubba, E. Using exergy to evaluate environmental externalities. In Proceedings of the IV NTVA Seminar of Industrial Ecology, Trondheim, Norway, June 14, 2001.

59. Favrat, D.; Marechal, F.; Epelly, O. The challenge of introducing an exergy indicator in a local law on energy. Energy 2007, In Press.

60. Szargut, J. Exergy Method-Technical and Ecological Applications; WIT Press: Boston, MA, USA, 2005.

61. Creyts, J.C.; Carey, V.P. Use of extended exergy analysis as a tool for assessment of the environmental impact of industrial processes. In Proceedings of the ASME Advanced Energy Systems Division; ASME: New York, NY, USA, 1997; pp. 129-137.

62. Hellstrom, D. An exergy analysis for a wastewater treatment plant: an estimation of the consumption of physical resources. Water Environ. Res. 1997, 69, 44-51.

63. Hellstrom, D. Exergy analysis of nutrient recovery processes. Water Sci. Technol. 2003, 48, 27-36.

64. Fraser, R.,A.; Kay, J. Establishing a role for thermal remote sensing of eco-systems: exergy analysis. In Thermal Remote Sensing in Land Surface Processes; Quattrochi, D., Luvall, J., Eds.; Taylor \& Francis: London, UK, 2003; Vol. 1, pp. 283-360.

65. Chen, G.Q. Scarcity of exergy and ecological evaluation based on embodied exergy. Commun. Nonlinear Sci. Numer. Simulat. 2006, 11, 531-552.

66. Connelly, L.; Koshland, C.P. Exergy and industrial ecology—part 1: an exergy-based definition of consumption and a thermodynamic interpretation of ecosystem evolution. Int. J. Exergy 2001, $1,146-165$.

67. Szargut, J.; Ziebik, A.; Stanek, W. Depletion of the non-renewable natural exergy resources as a measure of the ecological cost. Energ. Convers. Manage. 2002, 43, 1149-1163.

68. Sciubba, E. Cost analysis of energy conversion systems via a novel resource-based quantifier. Energy 2003, 28, 457-477.

69. Jorgensen, S.E. The Thermodynamic Concept: Exergy. In Thermodynamics and Ecological Modelling; Jorgensen, S.E., Ed.; Lewis Publishers: Boca Raton, FL, USA, 2001.

70. Jorgensen, S.E. Parameter estimation and calibration by use of exergy. Ecol. Model. 2001, 146, 299-302. 
71. Jorgensen, S.E.; Ladegaard, N.; Debeljak, M.; Marques, J.C. Calculations of exergy for organisms. Ecol. Model. 2005, 185, 165-175.

72. Jorgensen, S.E.; Mejer, H. Ecological buffer capacity. Ecol. Model. 1977, 3, 39-45.

73. Jorgensen, S.E.; Mejer, H.; Nielsen, S.N. Ecosystem as self-organizing critical systems. Ecol. Model. 1998, 111, 261-268.

74. Ahrendts, J. Reference states. Energy 1980, 5, 666-677.

75. Çengel, Y.A.; Çerçi, Y.; Wood, B. Second law analysis of separation processes of mixtures. In Proceedings of the ASME Advanced Energy Systems Division; ASME: New York, NY, USA, 1999; Vol. 39, pp. 537-543.

76. Bejan, A. Advanced Engineering Thermodynamics, 2nd ed.; Wiley-Interscience: New York, NY, USA, 1998; p. 850.

77. Azoumah, Y.; Blin, J.; Daho, T. Exergy efficiency applied for the performance optimization of a direct injection compression ignition (CI) engine using biofuels. Renewable Energy 2009, 34, 1494-1500.

78. Li, K.W. Applied Thermodynamics : Availability Method and Energy Conversion; Taylor \& Francis: Washington, DC, USA, 1996.

79. Garrido, J.G. Axiomatic basis of equilibrium classical thermodynamics. Erkenntnis 1986, 25, 239-263.

80. Gaudreau, K. Exergy Analysis and Resource Accounting; Master Thesis, University of Waterloo: Waterloo, Canada, 2009.

81. Mitsch, W.J.; Jorgensen, S.E. Ecological Engineering and Ecosystem Restoration, 2nd ed.; Wiley: Hoboken, NJ, USA, 2003; p. 424.

(C) 2009 by the authors; licensee Molecular Diversity Preservation International, Basel, Switzerland. This article is an open-access article distributed under the terms and conditions of the Creative Commons Attribution license (http://creativecommons.org/licenses/by/3.0/). 